\title{
The Future Therapy of Renal Cell Carcinoma? Non-Invasive Physical Plasma as an Innovative Oncological Therapy Modality
}

\author{
Andreas Nitsch ${ }^{1}$, Matthias Bernhard Stope ${ }^{2}$ \\ ${ }^{1}$ Department of Trauma, Reconstructive Surgery and Rehabilitation Medicine, University Medicine Greifswald, Greifswald, \\ Germany \\ ${ }^{2}$ Department of Gynecology and Gynecological Oncology, University Hospital Bonn, Bonn, Germany \\ Email: andreas.nitsch@med.uni-greifswald.de, matthias.stope@ukbonn.de
}

How to cite this paper: Nitsch, A. and Stope, M.B. (2021) The Future Therapy of Renal Cell Carcinoma? Non-Invasive Physical Plasma as an Innovative Oncological Therapy Modality. Journal of Cancer Therapy, 12, 602-610. https://doi.org/10.4236/jct.2021.1211052

Received: September 28, 2021

Accepted: November 2, 2021

Published: November 5, 2021

Copyright $\odot 2021$ by author(s) and Scientific Research Publishing Inc. This work is licensed under the Creative Commons Attribution International License (CC BY 4.0).

http://creativecommons.org/licenses/by/4.0/

(c) (i) Open Access

\begin{abstract}
Renal cell carcinoma (RCC) is one of the most important urological tumors and is one of the most common cancer diseases worldwide. Unfortunately, the treatment options are very limited due to resistances. Non-invasive physical plasma (NIPP) is currently becoming a promising and very well tolerated treatment option for cancer. NIPP represents a highly energized gas and induces varying antioncogenic cell responses in tumor cells. And also in the case of RCC, NIPP treatment has great potential to enhance and supplement existing anticancer treatment options. Outstanding characteristics of NIPP treatment are 1) a precise and local effect on the treated tissue and 2) an almost exclusive effect on treated tumor cells without side effects. This allows an enormously large therapeutic window and makes the combination of NIPP treatment and classical therapy appear particularly promising. In addition to RCC, plasma oncology offers an extremely innovative physical treatment method for future oncology in general. This brief review article summarizes the current knowledge on the potential use of NIPP in RCC therapy.
\end{abstract}

\section{Keywords}

Physical Plasma, Non-Invasive Physical Plasma, Cold Plasma, Plasma Medicine, Plasma Oncology, Renal Cell Carcinoma

\section{Introduction}

With an incidence of 17.4 new cases per 100,000 inhabitants in 2018, renal cell carcinoma (RCC) is one of the ten most common malignant diseases in Germany [1]. Among urological carcinomas, RCC is the third most common after pros- 
tate and bladder carcinomas. Men (25.1/100,000 inhabitants) are affected about twice as often as women (11.4/100,000 inhabitants) [1]. RCC accounts for $85 \%$ of kidney tumors [1] [2]. The mean age of onset is 68 years for men and 71 years for women [2] [3].

Tobacco consumption is considered a significant risk factor for RCC [4]. The risk increase is estimated to be $54 \%$ for men and $22 \%$ for women [5] [6] [7]. Overweight and high blood pressure also increases the risk of RCC [8] [9] [10]. Risk factors that cannot be influenced include terminal kidney failure [11] and familial high incidence of RCC [12]. The risk of developing RCC is $200 \%-400 \%$ higher in first- or second-degree relatives of an existing patient [12] [13]. Germline mutations of a hereditary tumor are responsible for $1 \%-4 \%$ of RCC [4]. These include von Hippel-Lindau syndrome, Birt-Hogg-Dubé syndrome, and hereditary leiomyomatosis [4].

RCC can be classified histologically. The most common entities are clear cell RCC (70\% - 80\%) and papillary RCC (15\%). Other entities account for only about $1 \%$ each [14] [15]. Staging is based on TNM and UICC criteria.

The prognosis of RCC is not excessively bad. The relative 5-year survival rate is over $75 \%$ [2]. However, the 5-year survival rate is strongly dependent on the tumor stage at initial diagnosis and decreases from more than $94 \%$ in stage I UICC (tumor up to $7 \mathrm{~cm}$, no lymph node or distant metastases) to less than $17 \%$ in stage IV (tumor infiltrates beyond the gerota fascia or distant metastases are present) [2] [16]. 15\% - 18\% of all RCC are already in stage IV at initial diagnosis [16].

\section{Current Renal Cell Carcinoma Therapies}

Previous therapy concepts have been dependent on the tumor stage and the general condition of the patient. Patients with extensive comorbidities and/or a limited life expectancy with small kidney tumors can be actively monitored [4] [17]. In these patients, focal therapy such as cryo- or radiofrequency ablation can also be applied [4] [18] [19] [20].

Surgical resection of the tumor is the focus of curative therapy [21]. For small localized tumors, kidney preserving surgery and partial nephrectomy should be performed [4] [19] [21] [22]. The standard procedure is open partial kidney resection according to the guidelines [4] [23] [24]. If a kidney preserving resection is not possible, a radical nephrectomy is performed [21]. In the treatment of patients with already metastasized RCC, palliative concepts are in the foreground [4]. In order to reduce the tumor burden, these patients will also be nephrectomized to reduce the tumor load, and if conditions are favorable (few, easily resectable metastases), a curative therapy concept can be pursued in patients in good general condition [4] [21] [25] [26].

Additionally to local surgical procedures a systemic therapy is applied. However, RCC show a high resistance to classical chemotherapeutic drugs [27]. The response rate of RCC to 5 -fluorouracil or floxuridine therapy is only $5 \%-8 \%$ 
[28]. Immunotherapies with interferon- $\alpha$ or interleukin- 2 show only slightly better response rates of $10 \%$ and $13 \%-21 \%$, respectively [29] [30]. Palliative chemotherapy or cytokine therapy should therefore not be performed in metastasized clear cell NCC [4] [31]. Chemoimmunotherapy should also be avoided according to the guideline [4]. The targeted drugs available today, such as tyrosine kinase and mTOR inhibitors, show a better response and have replaced classic chemotherapy and pure immunotherapy [4].

Sunitinib is recommended as a first-line treatment in patients with metastatic NCC and good or moderate prognosis [4] [31] [32] [33]. About $31 \%$ of patients respond to this therapy [31]. Treatment with sunitinib can extend median progression-free survival from 5 to 11 months [31]. Overall survival is also extended from 21.8 to 26.4 months [34]. Complete remission is rarely observed with sunitinib therapy [35]. Radiation therapy may be considered in palliative therapy concepts in the presence of brain/bone metastases, spinal compression and other symptomatic metastases, if the patient is in good general state of health [4] [36] [37] [38] [39].

\section{Non-Invasive Physical Plasma Treatment as Oncological Therapy}

Despite some therapeutic options, it still seems necessary to develop and evaluate further alternative procedures for RCC treatment. The efficacy of classical therapies is primarily limited by frequently occurring resistances. Treatment with non-invasive physical plasma (NIPP) offers an alternative. NIPP is a partially or completely ionized gas consisting of protons, neutrons, ions, free electrons, radicals, and electromagnetic radiation [40]. These components are in continuous interaction with each other and with the ambient atmosphere [40]. NIPP is formed by excitation of atoms and molecules of a gas when energy is supplied [40] [41]. Naturally occurring physical plasmas, such as stars, northern lights or thunderbolts, are hot plasmas with temperatures up to several million degrees Celsius [42]. NIPP have temperatures up to $45^{\circ} \mathrm{C}$ [43].

The application of artificially generated physical plasmas is widespread. While hot plasmas are used for welding or cutting metallic materials, NIPP can be used for sterilization of heat-sensitive materials, for example in food industry [44] [45] [46]. The antibacterial effect of NIPP is utilized in the treatment of wounds [47]. In addition, NIPP appears to promote wound healing by moderately activating acute inflammatory reactions and primary wound healing cascades [48]. This makes NIPP particularly suitable for the treatment of chronic and infected wounds [49] [50].

The application of NIPP in oncological therapy is a new promising indication [51] [52]. Various studies have shown an antiproliferative effect of NIPP on different cancer cells [53]. For example, an effect on skin tumors [54], breast [55], ovarian [56], and lung cancer cells [57] has been demonstrated. An interesting option seems to be the combination of NIPP with cytostatic drugs. NIPP treat- 
ment could improve the response of chemotherapy to cytostatic-resistant colorectal cancer cells [58].

The mechanisms of action of NIPP are not yet fully understood and are the subject of current studies. The causes of the antibacterial effect are discussed as damage to DNA by UV radiation, changes in membrane potential, impairment of membrane integrity, and the formation of reactive species [59] [60]. The antiproliferative effect of NIPP is due to the induction of apoptosis as well as the impairment of cell metabolism and membrane integrity (Figure 1) [61] [62].

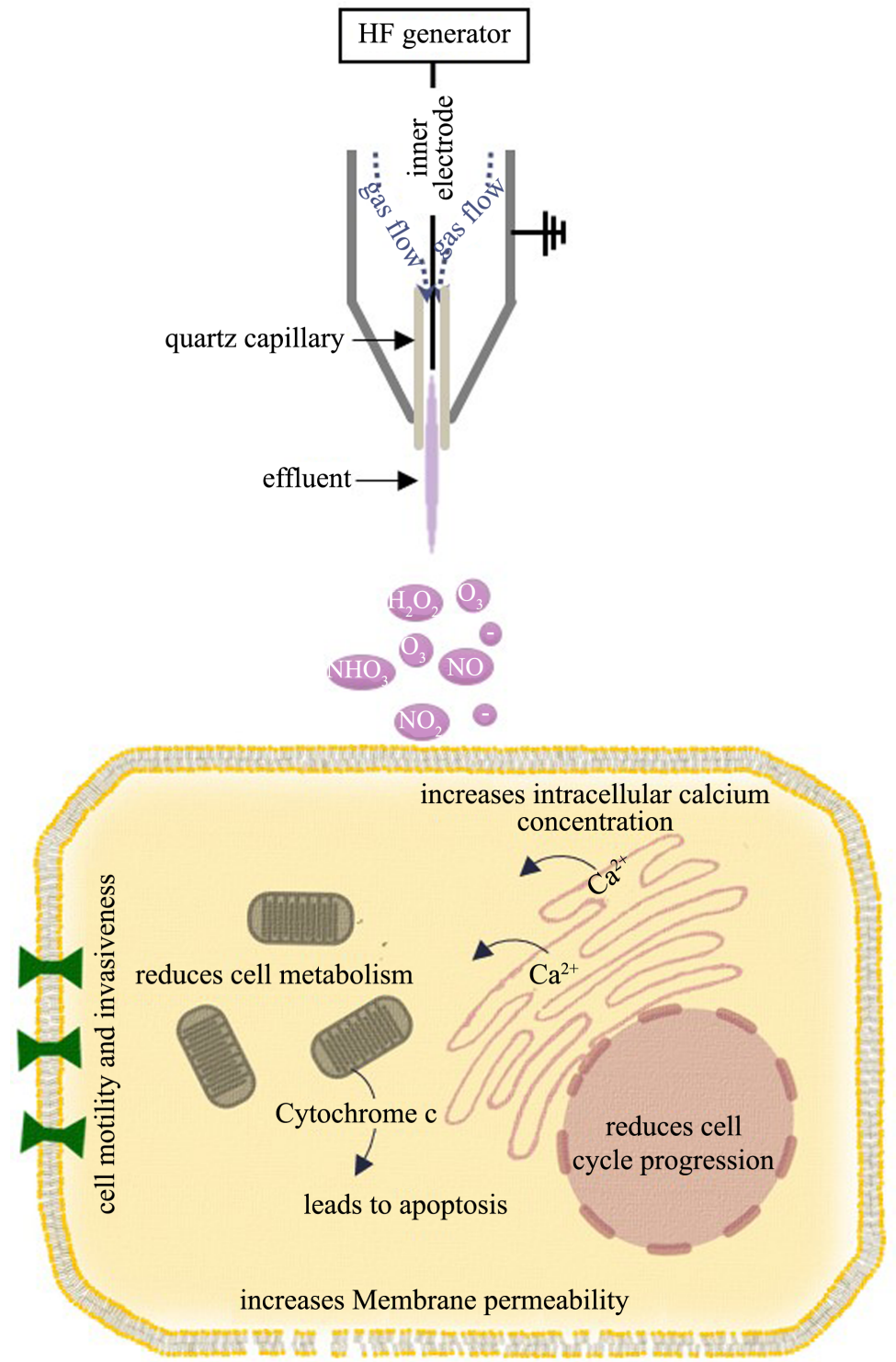

Figure 1. Antioncogenic activity of non-invasive physical plasma (NIPP). Reactive oxygen and nitrogen species are formed at the interface between NIPP and ambient atmosphere. These exert very different biological and primarily tumor suppressing effects on cancer cells. In renal cell carcinoma cells, treatment with NIPP leads to the release of intracellular $\mathrm{Ca}^{2+}$. Furthermore, cell motility and membrane functionality are impaired, the metabolism is lowered and the cell cycle machinery is restricted. Subsequently, apoptotic signaling pathways are induced and programmed cell death occurs. 
In addition to curative treatment approaches, NIPP could represent an extension of the treatment of palliative RCC patients. Compared to radiotherapy, NIPP offers several advantages. NIPP treatment does not induce necrosis and does severe or systemic inflammation [63]. Furthermore, the penetration depth of NIPP is comparatively low, so that tumor areas can be treated very precisely and no systemic effects occur. Finally, NIPP treatment requires considerably less equipment and is therefore much less expensive [63]. A prerequisite for the use of NIPP, however, is the reachability of the affected tissue sections. This poses a certain challenge in the treatment of RCC. In principle, the intraoperative use of endoscopic or laparoscopic techniques is therefore conceivable. However, to verify and further develop this is subject to future studies. Currently, there are no clinical data available.

\section{Conclusion}

In summary, NIPP treatment has great potential to enhance and supplement existing RCC treatment options. Outstanding characteristics of NIPP treatment are 1) a precise and local effect on the treated tissue and 2) an almost exclusive effect on treated tumor cells without side effects. This allows an enormously large therapeutic window and makes the combination of NIPP treatment and classical therapy appear particularly promising. In addition to RCC, plasma oncology offers an extremely innovative physical treatment method for future oncology in general.

\section{Conflicts of Interest}

The authors declare no conflicts of interest regarding the publication of this paper.

\section{References}

[1] Europäische Union (2020) ECIS-European Cancer Information System. https://ecis.jrc.ec.europa.eu

[2] Fiebig, J. and Kraywinkel, K. (2019) Epidemiologie des Nierenzellkarzinoms in Deutschland. Der Onkologe, 25, 483-487. https://doi.org/10.1007/s00761-019-0580-7

[3] Doehn, C., Grünwald, V., Steiner, T., Follmann, M., Rexer, H. and Krege, S. (2016) Diagnostik, Therapie und Nachsorge des Nierenzellkarzinoms. Deutsches Ärzteblatt International, 113, 590-596.

[4] Leitlinienprogramm Onkologie (2017) Diagnostik, Therapie und Nachsorge des Nierenzellkarzinoms. http://leitlinienprogramm-onkologie.de/Nierenzellkarzinom.85.0.html

[5] Hu, J., Ugnat, A.-M. and die Canadian Cancer Registries Epidemiology Research Group (2005) Active and Passive Smoking and Risk of Renal Cell Carcinoma in Canada. European Journal of Cancer, 41, 770-778. https://doi.org/10.1016/j.ejca.2005.01.003

[6] Theis, R.P., Dolwick Grieb, S.M., Burr, D., Siddiqui, T. and Asal, N.R. (2008) Smoking, Environmental Tobacco Smoke, and Risk of Renal Cell Cancer: A Population-Based Case-Control Study. BMC Cancer, 8, 387. https://doi.org/10.1186/1471-2407-8-387

[7] Parker, A.S., Cerhan, J.R., Janney, C.A., Lynch, C.F. and Cantor, K.P. (2003) Smok- 
ing Cessation and Renal Cell Carcinoma. Annals of Epidemiology, 13, 245-251. https://doi.org/10.1016/S1047-2797(02)00271-5

[8] Renehan, A.G., Tyson, M., Egger, M., Heller, R.F. and Zwahlen, M. (2008) Body-Mass Index and Incidence of Cancer: A Systematic Review and Meta-Analysis of Prospective Observational Studies. The Lancet, 371, 569-578. https://doi.org/10.1016/S0140-6736(08)60269-X

[9] Flaherty, K.T., et al. (2005) A Prospective Study of Body Mass Index, Hypertension, and Smoking and the Risk of Renal Cell Carcinoma (United States). Cancer Causes \& Control: CCC, 16, 1099-1106. https://doi.org/10.1007/s10552-005-0349-8

[10] Choi, M.Y., Jee, S.H., Sull, J.W. and Nam, C.M. (2005) The Effect of Hypertension on the Risk for Kidney Cancer in Korean Men. Kidney International, 67, 647-652. https://doi.org/10.1111/j.1523-1755.2005.67137.x

[11] Port, F.K., Ragheb, N.E., Schwartz, A.G. and Hawthorne, V.M. (1989) Neoplasms in Dialysis Patients: A Population-Based Study. American Journal of Kidney Diseases, 14, 119-123. https://doi.org/10.1016/S0272-6386(89)80187-8

[12] Gago-Dominguez, M., Yuan, J.M., Castelao, J.E., Ross, R.K. and Yu, M.C. (2001) Family History and Risk of Renal Cell Carcinoma. Cancer Epidemiology, Biomarkers \& Prevention, 10, 1001-1004.

[13] Clague, J., et al. (2009) Family History and Risk of Renal Cell Carcinoma: Results from a Case-Control Study and Systematic Meta-Analysis. Cancer Epidemiology, Biomarkers \& Prevention, 18, 801-807. https://doi.org/10.1158/1055-9965.EPI-08-0601

[14] Moch, H., Cubilla, A.L., Humphrey, P.A., Reuter, V.E. and Ulbright, T.M. (2016) The 2016 WHO Classification of Tumours of the Urinary System and Male Genital Organs Part A: Renal, Penile, and Testicular Tumours. European Urology, 70, 93-105. https://doi.org/10.1016/j.eururo.2016.02.029

[15] Cohen, H.T. and McGovern, F.J. (2005) Renal-Cell Carcinoma. The New England Journal of Medicine, 353, 2477-2490. https://doi.org/10.1056/NEJMra043172

[16] Kaatsch, P., et al. (2019) Niere. Krebs in Deutschland für, 2015/2016, 106-109.

[17] Smaldone, M.C., et al. (2012) Small Renal Masses Progressing to Metastases under Active Surveillance: A Systematic Review and Pooled Analysis. Cancer, 118, 997-1006. https://doi.org/10.1002/cncr.26369

[18] Siva, S., Pham, D., Gill, S., Corcoran, N.M. and Foroudi, F. (2012) A Systematic Review of Stereotactic Radiotherapy Ablation for Primary Renal Cell Carcinoma. BJU International, 110, 737-743. https://doi.org/10.1111/j.1464-410X.2012.11550.x

[19] MacLennan, S., et al. (2012) Systematic Review of Oncological Outcomes Following Surgical Management of Localised Renal Cancer. European Urology, 61, 972-993. https://doi.org/10.1016/j.eururo.2012.02.039

[20] El Dib, R., Touma, N.J. and Kapoor, A. (2012) Cryoablation vs Radiofrequency Ablation for the Treatment of Renal Cell Carcinoma: A Meta-Analysis of Case Series Studies. BJU International, 110, 510-516. https://doi.org/10.1111/j.1464-410X.2011.10885.x

[21] Ljungberg, B., et al. (2019) European Association of Urology Guidelines on Renal Cell Carcinoma: The 2019 Update. European Urology, 75, 799-810. https://doi.org/10.1016/j.eururo.2019.02.011

[22] MacLennan, S., et al. (2012) Systematic Review of Perioperative and Quality-of-Life Outcomes Following Surgical Management of Localised Renal Cancer. European Urology, 62, 1097-1117. https://doi.org/10.1016/j.eururo.2012.07.028

[23] Gill, I.S., et al. (2007) Comparison of 1,800 Laparoscopic and Open Partial Neph- 
rectomies for Single Renal Tumors. The Journal of Urology, 178, 41-46. https://doi.org/10.1016/j.juro.2007.03.038

[24] Lane, B.R. and Gill, I.S. (2010) 7-Year Oncological Outcomes after Laparoscopic and Open Partial Nephrectomy. The Journal of Urology, 183, 473-479. https://doi.org/10.1016/j.juro.2009.10.023

[25] Alt, A.L., Boorjian, S.A., Lohse, C.M., Costello, B.A., Leibovich, B.C. and Blute, M.L. (2011) Survival after Complete Surgical Resection of Multiple Metastases from Renal Cell Carcinoma. Cancer, 117, 2873-2882. https://doi.org/10.1002/cncr.25836

[26] Eggener, S.E., Yossepowitch, O., Kundu, S., Motzer, R.J. and Russo, P. (2008) Risk Score and Metastasectomy Independently Impact Prognosis of Patients with Recurrent Renal Cell Carcinoma. The Journal of Urology, 180, 873-878. https://doi.org/10.1016/j.juro.2008.05.006

[27] Motzer, R.J., Bander, N.H. and Nanus, D.M. (1996) Renal-Cell Carcinoma. The New England Journal of Medicine, 335, 865-875. https://doi.org/10.1056/NEJM199609193351207

[28] Hartmann, J.T. and Bokemeyer, C. (1999) Chemotherapy for Renal Cell Carcinoma. Anticancer Research, 19, 1541-1543.

[29] Minasian, L.M., Motzer, R.J., Gluck, L., Mazumdar, M., Vlamis, V. and Krown, S.E. (1993) Interferon alfa-2a in Advanced Renal Cell Carcinoma: Treatment Results and Survival in 159 Patients with Long-Term Follow-Up. Journal of Clinical Oncology, 11, 1368-1375. https://doi.org/10.1200/JCO.1993.11.7.1368

[30] Yang, J.C., et al. (2003) Randomized Study of High-Dose and Low-Dose Interleukin-2 in Patients with Metastatic Renal Cancer. Journal of Clinical Oncology, 21, 3127-3132. https://doi.org/10.1200/JCO.2003.02.122

[31] Motzer, R.J., et al. (2007) Sunitinib versus Interferon Alfa in Metastatic Renal-Cell Carcinoma. The New England Journal of Medicine, 356, 115-124. https://doi.org/10.1056/NEJMoa065044

[32] Motzer, R.J., et al. (2013) Pazopanib versus Sunitinib in Metastatic Renal-Cell Carcinoma. The New England Journal of Medicine, 369, 722-731. https://doi.org/10.1056/NEJMoa1303989

[33] Escudier, B., et al. (2007) Bevacizumab plus Interferon Alfa-2a for Treatment of Metastatic Renal Cell Carcinoma: A Randomised, Double-Blind Phase III Trial. The Lancet, 370, 2103-2111. https://doi.org/10.1016/S0140-6736(07)61904-7

[34] Motzer, R.J., et al. (2009) Overall Survival and Updated Results for Sunitinib Compared with Interferon Alfa in Patients with Metastatic Renal Cell Carcinoma. Journal of Clinical Oncology, 27, 3584-3590. https://doi.org/10.1200/JCO.2008.20.1293

[35] Albiges, L., et al. (2012) Complete Remission with Tyrosine Kinase Inhibitors in Renal Cell Carcinoma. Journal of Clinical Oncology, 30, 482-487. https://doi.org/10.1200/JCO.2011.37.2516

[36] Chow, E., Zeng, L., Salvo, N., Dennis, K., Tsao, M. and Lutz, S. (2012) Update on the Systematic Review of Palliative Radiotherapy Trials for Bone Metastases. Clinical Oncology, 24, 112-124. https://doi.org/10.1016/j.clon.2011.11.004

[37] Lutz, S. (2012) The Role of Radiation Therapy in Controlling Painful Bone Metastases. Current Pain and Headache Reports, 16, 300-306. https://doi.org/10.1007/s11916-012-0271-1

[38] Rades, D., Weber, A., Bartscht, T., Bajrovic, A., Karstens, J.H. and Schild, S.E. (2014) A New Prognostic Factor for the Survival of Patients with Renal Cell Carcinoma Developing Metastatic Spinal Cord Compression. Strahlentherapie und On- 
kologie, 190, 667-670. https://doi.org/10.1007/s00066-014-0616-2

[39] Dziggel, L., Segedin, B., Podvrsnik, N.H., Oblak, I., Schild, S.E. and Rades, D. (2014) A Survival Score for Patients with Brain Metastases from Less Radiosensitive Tumors Treated with Whole-Brain Radiotherapy Alone. Strahlentherapie und Onkologie, 190, 54-58. https://doi.org/10.1007/s00066-013-0394-2

[40] Moisan, M., Barbeau, J., Moreau, S., Pelletier, J., Tabrizian, M. and Yahia, L.H. (2001) Low-Temperature Sterilization Using Gas Plasmas: A Review of the Experiments and an Analysis of the Inactivation Mechanisms. International Journal of Pharmaceutics, 226, 1-21. https://doi.org/10.1016/S0378-5173(01)00752-9

[41] Gay-Mimbrera, J., García, M., Tejera, B., Rodero, A., Antonio Vélez García, N. and Ruano, J. (2016) Clinical and Biological Principles of Cold Atmospheric Plasma Application in Skin Cancer. Advances in Therapy, 33, 894-909. https://doi.org/10.1007/s12325-016-0338-1

[42] Hoffmann, C., Berganza, C. and Zhang, J. (2013) Cold Atmospheric Plasma: Methods of Production and Application in Dentistry and Oncology. Medical Gas Research, 3, 21. https://doi.org/10.1186/2045-9912-3-21

[43] Lee, H., Shon, C., Kim, Y., Kim, S., Kim, G. and Kong, M.G. (2009) Degradation of Adhesion Molecules of G361 Melanoma Cells by a Non-Thermal Atmospheric Pressure Microplasma. New Journal of Physics, 11, Article ID: 115026. https://doi.org/10.1088/1367-2630/11/11/115026

[44] Von Woedtke, T., Kramer, A. and Weltmann, K.-D. (2008) Plasma Sterilization: What Are the Conditions to Meet This Claim? Plasma Processes and Polymers, 5, 534-539. https://doi.org/10.1002/ppap.200800013

[45] Laroussi, M. (2008) The Biomedical Applications of Plasma: A Brief History of the Development of a New Field of Research. IEEE Transactions on Plasma Science, 36, 1612-1614. https://doi.org/10.1109/TPS.2008.917167

[46] Ziuzina, D., Patil, S., Cullen, P.J., Keener, K.M. and Bourke, P. (2014) Atmospheric Cold Plasma Inactivation of Escherichia coli, Salmonella enterica Serovar Typhimurium and Listeria monocytogenes Inoculated on Fresh Produce. Food Microbiology, 42, 109-116. https://doi.org/10.1016/j.fm.2014.02.007

[47] Heinlin, J., et al. (2011) Plasma Applications in Medicine with a Special Focus on Dermatology. The Journal of the European Academy of Dermatology and Venereology, 25, 1-11. https://doi.org/10.1111/j.1468-3083.2010.03702.x

[48] Leonarduzzi, G., Sottero, B. and Poli, G. (2010) Targeting Tissue Oxidative Damage by Means of Cell Signaling Modulators: The Antioxidant Concept Revisited. Pharmacology \& Therapeutics, 128, 336-374. https://doi.org/10.1016/j.pharmthera.2010.08.003

[49] Isbary, G., et al. (2010) A First Prospective Randomized Controlled Trial to Decrease Bacterial Load Using Cold Atmospheric Argon Plasma on Chronic Wounds in Patients. The British Journal of Dermatology, 163, 78-82. https://doi.org/10.1111/j.1365-2133.2010.09744.x

[50] Mohd Nasir, N., Lee, B.K., Yap, S.S., Thong, K.L. and Yap, S.L. (2016) Cold Plasma Inactivation of Chronic Wound Bacteria. Archives of Biochemistry and Biophysics, 605, 76-85. https://doi.org/10.1016/j.abb.2016.03.033

[51] Dezest, M., et al. (2017) Mechanistic Insights into the Impact of Cold Atmospheric Pressure Plasma on Human Epithelial Cell Lines. Scientific Reports, 7, Article No. 41163. https://doi.org/10.1038/srep41163

[52] Keidar, M., et al. (2012) Cold Atmospheric Plasma in Cancer Therapy. Physics of Plasmas, 20, Article ID: 057101. https://doi.org/10.1063/1.4801516 
[53] Yan, D., Sherman, J.H. and Keidar, M. (2017) Cold Atmospheric Plasma, a Novel Promising Anti-Cancer Treatment Modality. Oncotarget, 8, 15977-15995. https://doi.org/10.18632/oncotarget.13304

[54] Xia, J., et al. (2019) Cold Atmospheric Plasma Induces Apoptosis of Melanoma Cells via Sestrin2-Mediated Nitric Oxide Synthase Signaling. Journal of Biophotonics, 12, 1-14. https://doi.org/10.1002/jbio.201800046

[55] Kim, S.J., Chung, T.H., Bae, S.H. and Leem, S.H. (2010) Induction of Apoptosis in Human Breast Cancer Cells by a Pulsed Atmospheric Pressure Plasma Jet. Applied Physics Letters, 97, Article ID: 023702. https://doi.org/10.1063/1.3462293

[56] Koensgen, D., et al. (2017) Cold Atmospheric Plasma (CAP) and CAP-Stimulated Cell Culture Media Suppress Ovarian Cancer Cell Growth-A Putative Treatment Option in Ovarian Cancer Therapy. Anticancer Research, 37, 6739-6744. https://doi.org/10.21873/anticanres.12133

[57] Kim, J.Y., et al. (2011) Apoptosis of Lung Carcinoma Cells Induced by a Flexible Optical Fiber-Based Cold Microplasma. Biosensors \& Bioelectronics, 28, 333-338. https://doi.org/10.1016/j.bios.2011.07.039

[58] Ishaq, M., Evans, M.D.M. and Ostrikov, K.K. (2014) Atmospheric Pressure Gas Plasma-Induced Colorectal Cancer Cell Death Is Mediated by Nox2-ASK1 Apoptosis Pathways and Oxidative Stress Is Mitigated by Srx-Nrf2 Anti-Oxidant System. Biochimica et Biophysica Acta, 1843, 2827-2837. https://doi.org/10.1016/j.bbamcr.2014.08.011

[59] Laroussi, M. (2009) Low-Temperature Plasmas for Medicine? IEEE Transactions on Plasma Science, 37, 714-725. https://doi.org/10.1109/TPS.2009.2017267

[60] Dobrynin, D., Fridman, G., Friedman, G. and Fridman, A. (2009) Physical and Biological Mechanisms of Direct Plasma Interaction with Living Tissue. New Journal of Physics, 11, Article ID: 115020. https://doi.org/10.1088/1367-2630/11/11/115020

[61] Sensenig, R., et al. (2011) Non-Thermal Plasma Induces Apoptosis in Melanoma Cells via Production of Intracellular Reactive Oxygen Species. Annals of Biomedical Engineering, 39, 674-687. https://doi.org/10.1007/s10439-010-0197-x

[62] Partecke, L.I., et al. (2012) Tissue Tolerable Plasma (TTP) Induces Apoptosis in Pancreatic Cancer Cells in Vitro and in Vivo. BMC Cancer, 12, 473. https://doi.org/10.1186/1471-2407-12-473

[63] Ishaq, M., Evans, M. and Ostrikov, K. (2014) Effect of Atmospheric Gas Plasmas on Cancer Cell Signaling. International Journal of Cancer, 134, 1517-1528. https://doi.org/10.1002/ijc.28323 